\title{
A Rare Case Report: Caudal Regression Syndrome in the Baby of a Mother with Hypothyroidism
}

\author{
Yusuf Atakan Baltrak, ${ }^{1}$ (D) Seniha Esin Söğüt, ${ }^{1}$ (D) Onursal Varlıklı, ${ }^{1}$ \\ D Nazan Karadeniz ${ }^{2}$ \\ 'Department of Pediatric Surgery, Health Sciences University Kocaeli Derince Training and \\ Research Hospital, Kocaeli, Turkey \\ ${ }^{2}$ Department of Obstetrics and Gynecology, Health Sciences University Kocaeli Derince Training \\ and Research Hospital, Kocaeli, Turkey
}

\section{ABSTRACT}

Caudal regression syndrome (CRS) is part of a spectrum of conditions that include imperforate anus, sacral agenesis and syringomyelia. Most cases of caudal regression are sporadic or associated with gestational diabetes. In this case study, we describe a case of characteristic CRS in a patient of a mother with hypothyroidism with anal atresia, flexion contracture on the hips and knees, pes equinovarus, and the absence of a sacrum and coccyx.

Keywords: Anal atresia, congenital abnormalities, hypothyroidism, imperforate anus

Please cite this article as: Baltrak YA, Söğüt SE, Varlıklı O, Karadeniz N. A Rare Case Report: Caudal Regression Syndrome in the Baby of a Mother with Hypothyroidism. Anatol J Family Med 2021;4(1):92-94.

Address for correspondence: Dr. Yusuf Atakan Baltrak. Department of Pediatric Surgery, Health Sciences University Kocaeli Derince Training and Research Hospital, Kocaeli, Turkey

Phone: +90 5054897503

E-mail:

dratakanbaltrak@gmail.com

Received Date: 10.02.2020

Accepted Date: 30.05 .2020

Published online: 10.03.2021

(C) Copyright 2021 by Anatolian Journal of Family Medicine -

Available online at

Www.anatoljfm.org

OPEN ACCESS

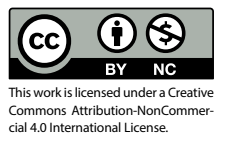

\section{INTRODUCTION}

Caudal regression syndrome (CRS) is a rare sporadic disorder characterized by congenital abnormalities of the lower limbs, gastrointestinal system and urogenital system, and affects the terminal spinal segment. ${ }^{[1-3]}$ Although the exact cause remains unknown, some environmental factors, genetic tendency and vascular hypoperfusion were suggested as possible causes. ${ }^{[3,4]}$ Many studies reported that CRS occurs 200 to 250-fold more in the babies of mothers with insulin-dependent diabetes mellitus. ${ }^{[1,2,5]}$

This case report aims to present a rare case with CRS and anal atresia detected in the baby of a mother with hypothyroidism.

\section{CASE REPORT}

The case was delivered as the first male baby of a 20-year old primigravida mother through caesarean section at $39^{\text {th }}$ gestational week. The mother had a history of levothyroxine sodium use at a dose of $25 \mathrm{mg}$ because of hypothyroidism. The history taken from the mother revealed that she was followed without any problem during the pregnancy, however, perinatological examination was not conducted. APGAR scores of the patient at minutes 1 and 5 were 9 and 10, respectively. The birth weight of the baby was $2.410 \mathrm{~g}$, his length was $45 \mathrm{~cm}(<3 \%)$ and head circumference was $34.5 \mathrm{~cm}$ (25-50p). The first physical examination revealed flexion contracture of the hip and knees as well as anal atresia (Fig. 1). The direct x-ray imaging demonstrated that there was not any sacrum and coccyx (Fig. 2a). Since anal concavity did not exist and meconium was detected in the urine analysis, the colostomy procedure was decided. A small secundum atrial septal defect was diagnosed in cardiac Echocardiography. No sacrum 


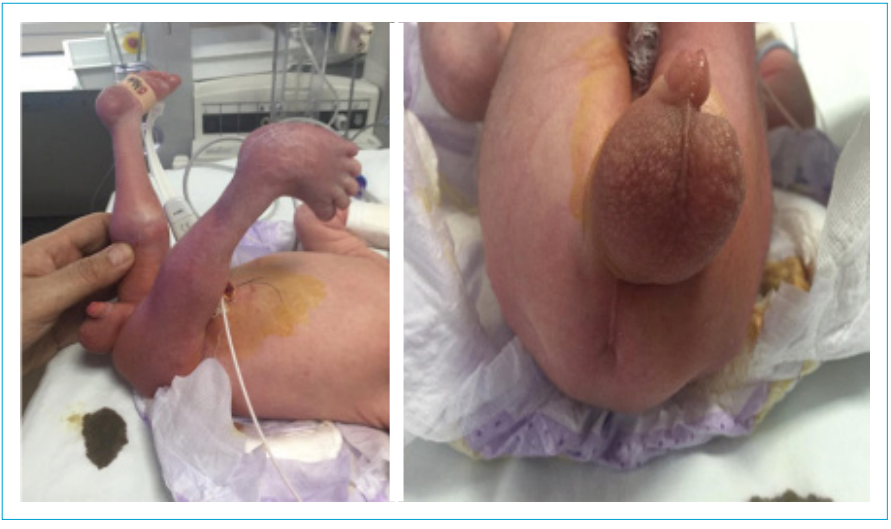

Figure 1. Flexion contracture and anal atresia of patient.

was observed in spinal ultrasonography for differential diagnosis. A cyst of $2.5 \mathrm{~cm}$ was detected at the end of the lower lumbar vertebra. Magnetic resonance imaging of the lumbosacral area was suggested for CRS evaluation. Magnetic resonance imaging was also reported to end at the T8 level of the medulla spinalis (Fig. 2b). The case was diagnosed with CRS after clinical and imaging findings were evaluated. The current treatment of the patient was carried out together with pediatric neurology, neurosurgery and physical therapy clinics. Colostomy care and physical exercise training were carried out by the family.

\section{DISCUSSION}

CRS was first identified by Duhamel ${ }^{[6]}$ CRS is a developmental abnormality of the caudal vertebra, neural tube, urogenital system, gastrointestinal system and lower limbs originated from the caudal canal during the intrauterine period. Various types of anorectal malformations, spinal segment agenesis, multiple visceral abnormalities and musculoskeletal system abnormalities may be detected..$^{[7]}$ The incidence of this condition is 1 per 60.000 births with a male/female ratio of $2.7 / 1$. The risk of recurrence is quite low. ${ }^{[8]}$

Although the aetiology and pathogenic mechanism could not be clarified, maternal diabetes, genetic predisposition, and vascular hypoperfusion are considered as possible causes. There is evidence that gestational diabetes may contribute to CRS. ${ }^{[9,10]}$ Experimental studies demonstrated that maternal use of retinoic acid, minoxidil and trimethoprim-sulphometoxasole caused CRS. ${ }^{[3]}$ Chromosome analyses were found normal beyond some exemptions. ${ }^{[11]}$

Intellectual functions are usually unaffected. Such patients would have a normal life except problems on the lower limb and neuromuscular deficit of the urinary bladder sphincter. The prognosis is poor in much-affected patients. ${ }^{[12,13]}$ Colostomy procedure was decided in our case due to

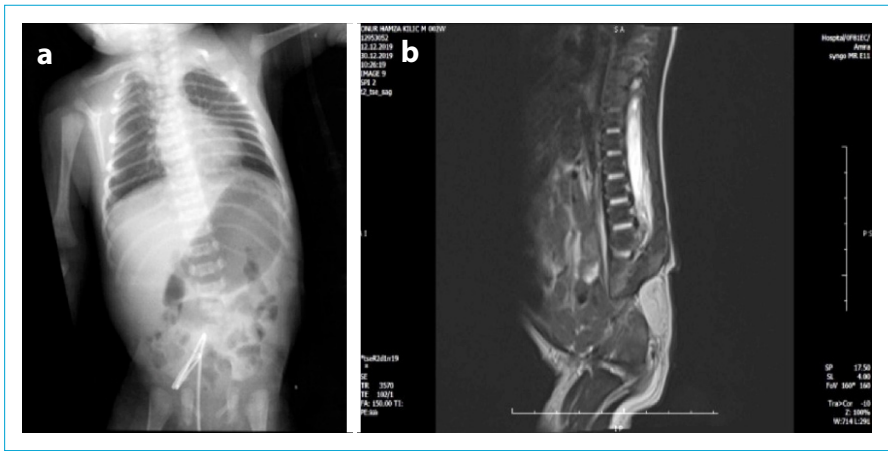

Figure 2. (a) Direct x-ray imaging of patient. (b) Magnetic resonance imaging of patient.

the clinical presentation of anal atresia concomitant with urethral fistula.

The abnormalities detected in this syndrome include pes ecinovarus and calcaneovarus, flexion contracture on the hips and knees, hip dislocation, agenesis of the sacrum and/or coccyx, agenesis of the fibula, rib fusion, syndactyly, polydactyly, cleft lip, cleft palate, tracheoesophageal fistula, abdominal wall defect, inguinal hernia, duodenal atresia, imperforate anus, renal agenesia or dysplasia, hydronephrosis, transposition of the external genitalia, hypospadias, microcephalia, hydrocephalus, meningomyelocele, partial agenesis of the corpus callosum and partial lobar holoprosencephaly. ${ }^{[5,13,14]}$

Our case had anal atresia, flexion contracture of the hip and knees, sacral and coccygeal agenesis, external rotation of the right lower limb and left pes equinovarus. The case was diagnosed with CRS due to the findings obtained.

The expected life period is long in such cases if vital organs are not affected. ${ }^{[15]}$ Prenatal diagnosis may be established by sudden spinal interruption due to vertebral agenesis and frog leg-like position of lower limbs in the ultrasound scan at 20th gestational week. However, the cases with severe CRS (sirenomelic fetus) may be diagnosed with transvaginal ultrasound at 16 th to 19 th gestational weeks. ${ }^{[9,13,16,17]}$

The present case with CRS was presented to draw attention to the prenatal diagnosis of the syndrome and to show the existence of this syndrome in the baby of a mother with hypothyroidism. This syndrome may be diagnosed by prenatal diagnosis, and pathological pregnancy may be terminated.

\section{Disclosures}

Informed Consent: Written informed consent was obtained from the patient's family to publish the case report and accompanying images. 
Conflict of Interest: The authors did not report any conflict of interest on this manuscript.

Peer-review: Externally peer-reviewed.

Authorship contributions: Concept - Y.A.B., O.V. Design - S.E.S., O.V.; Supervision - O.V., S.E.S.; Materials - O.V., Y.A.B.; Data collection \&/or processing - Y.A.B., O.V.; Analysis and/or interpretation - S.E.S., O.V.; Literature search - Y.A.B., O.V.; Writing - Y.A.B., S.E.S.; Critical Review - Y.A.B.

\section{REFERENCES}

1. Lynch SA, Wang Y, Strachan T, Burn J, Lindsay S. Autosomal dominant sacral agenesis: Currarino syndrome. J Med Genet 2000;37(8):561-6. [CrossRef]

2. Kalter H. Case reports of malformations associated with maternal diabetes: history and critique. Clin Genet 1993;43(4):1749. [CrossRef]

3. Singh SK, Singh RD, Sharma A. Caudal regression syndrome--case report and review of literature. Pediatr Surg Int 2005;21(7):578-81. [CrossRef]

4. Hentschel J, Stierkorb E, Schneider G, Goedde S, Siemer S, Gortner L. Caudal regression sequence: vascular origin? J Perinatol 2006;26(7):445-7. [CrossRef]

5. Zaw W, Stone DG. Caudal Regression Syndrome in twin pregnancy with type II diabetes. J Perinatol 2002;22(2):171-4.

6. Duhamel B. From the mermaid to anal imperforation: the syndrome of caudal regression. Arch Dis Child 1961;36(186):1525. [CrossRef]

7. Pang D. Sacral agenesis and caudal spinal cord malformations. Neurosurgery 1993;32(5):755-78; discussion 778-9. [CrossRef]

8. Jaffe R, Zeituni M, Fejgin M. Caudal regresion syndrome. Fetus
Spinal Anom 1991;7561:1-3.

9. Valenzano M, Paoletti R, Rossi A, Farinini D, Garlaschi G, Fulcheri E. Sirenomelia. Pathological features, antenatal ultrasonographic clues, and a review of current embryogenic theories. Hum Reprod Update 1999;5(1):82-6. [CrossRef]

10. Versiani BR, Gilbert-Barness E, Giuliani LR, Peres LC, Pina-Neto JM. Caudal dysplasia sequence: severe phenotype presenting in offspring of patients with gestational and pregestational diabetes. Clin Dysmorphol 2004;13(1):1-5. [CrossRef]

11. Perrot LJ, Williamson $S$, Jimenez JF. The caudal regression syndrome in infants of diabetic mothers. Ann Clin Lab Sci 1987;17(4):211-20.

12. Currarino G, Coln D, Votteler T. Triad of anorectal, sacral, and presacral anomalies. AJR Am J Roentgenol 1981;137(2):395-8.

13. Jones KL. Caudal dysplasia sequence. Smith's recognizable patterns of human malformation. 6th ed. Philadelphia: Elsevier Saunders; 2006. p. 730-1.

14. Hashami HA, Bataclan MF, Mathew M, Krishnan L. Caudal regression syndrome with partial agenesis of the corpus callosum and partial lobar holoprosencephaly: case report. Sultan Qaboos Univ Med J 2010;10(1):89-93.

15. Singh A, Kapoor S, Pradhan G, Gautam VK, Ratan SK. Scoliotic deformity and asymptomatic cervical syrinx in a 9 year old with caudal regression syndrome. J Pediatr Neurosci 2012;7(3):191-3. [CrossRef]

16. Aslan H, Yanik H, Celikaslan N, Yildirim G, Ceylan Y. Prenatal diagnosis of caudal regression syndrome: a case report. BMC Pregnancy Childbirth 2001;1(1):8. [CrossRef]

17. Mandour C, El Mostarchid B. A rare congenital malformation: caudal regression syndrome. Pan Afr Med J 2013;14:30. [CrossRef] 